\title{
CONSUMING APPS: THE AUSTRALIAN WOMAN'S SLOW APPETITE FOR APPS
}

\author{
Scott Rickard \\ Smart Services CRC, Swinburne University of Technology \\ Clare Lloyd \\ Department of Internet Studies, Curtin University
}

\begin{abstract}
This article explores the domestication of mobile technologies by women and how their traditionally slow adoption of new technologies is being mirrored through their adoption of smart-phone applications. Building on existing gender and mobile communications literature, this paper provides a needed overview of how women are strategically deploying the use of 'apps' on their smart phones in both 'fun' and 'useful' ways.
\end{abstract}

Two groups are analysed in this article. The first comprises women who only use a single Internet connection, identified as 'single connectors'. This group is contrasted with a second group who use multiple Internet connections, identified as 'triple connectors'. In this article we playfully name the social seeking Triple Connectors Social Consumers and the Mobile Internet Single Connectors have been identified as Information Seeking Consumers. 'Social networking' was identified as a 'fun' app rather than a 'useful' app by both groups of female connectors: what does this say about women and their definitions of leisure? Are women still viewing networking as part of their commitment to emotional labour rather than something that is 'useful'?

\section{INTRODUCTION}

Australians have a growing appetite for apps that enable them to perform a range of tasks from mobile banking through to selecting a restaurant (AIMIA 2010, 86). Worldwide, $60 \%$ of smart-phone users download an app every month, paying on average $\$ 4.00$ to do so (Fraser 2011). Convergent devices such as smart-phones provide busy Australians with the opportunity for immediate communication through voice or data. While voice is seen as essential for intimate contact with loved ones (Licoppe 2004, Lloyd 2010) it is Internet data services that continue to drive growth in the take-up of mobile services rather than voice (ACMA 2011, 19). Initially, interest was piqued with telephony data in the form of short message service (SMS) and multimedia message service (MMS) (Goggin 2006). Australian uptake of texting grew unexpectedly fast providing telecommunications providers with 'continual growth' (ACMA 2010, 50) and the recognition that possible future data services could outstrip voice sales. The sending or receiving of SMS messages remains the most popular non-voice activity (84\% received and 83\% sent) in 2011 (ACMA 2011, 42). Smartphones offer end users the enticing combination of voice and Internet data, so enabling communication, information seeking and transactions in the one converged device. Australians are increasing their transactions through their phones; PayPal Australia reports that throughout 2010 mobile transactions increased by 25\% every month (Moses 2011). As part of this shift to mobile usage Ryan Hayward, Google's mobile product marketing manager for the Asian-Pacific region states that 'mobile usage and smart-phone usage (is) starting to 
approach or even match PC usage...we found that Google Maps...usage on the mobile phone has already exceeded the desktop globally' (Moses 2011).

The 2010 AIMIA report confirmed 'Australians' increasing consumption of data via their smart-phones. AIMIA noted an increase in those that had data included in their payment plan, up 16\% from 2009, as well as an increase in the amount of data included in plans (Mackay 2010 , 4). There was a $19 \%$ increase in the more than 50MB category and a spike in the 251500MB category from 6\% to 19\% (Mackay 2010).

While women are often seen as the later adopters of technology to men, when women do adopt technology it is usually for social rather than business or professional purposes. This can be seen in a range of technologies from Fischers' (1988) seminal investigations with the telephone in the 1980s, which uncovered that historically women used the telephone for social connectedness, while men used it for business through to even earlier explorations with long distance telegraphy (Sterne 2003). With these findings in mind it might be extrapolated that women might prefer applications or 'apps' as they are known, for their phones that enabled greater communication through the multiple methods currently available text, voice, and video.

\section{RELEVANT LITERATURE}

\section{AUSTRALIANS' USE OF APPS}

Currently $12 \%$ of product share of online retail sales in Australia is attributable to software and apps (ACMA 2011b, 10). In relation to fun apps in AIMIA's results for 2010 '66\% stated that they used an entertainment or information service' during the last twelve months, and '48\% of all respondents used games' (Mackay 2010, 6). These figures do not include Mobile Internet specific data downloads. Only 31\% of AIMIA's respondents use Mobile Internet to access entertainment services and content (Mackay 2010, 7). However while there are hundreds of thousands of apps to download and use on smart phones and tablets (Fraser 2011), there is little investigation into actual end user preferences for apps. Total downloads of apps is a commonly used measure; however it does not reflect consumer preferences for the app once they have begun to use it. It is possible that after downloading an app a consumer becomes dissatisfied with the product and they may even delete it from their device. This paper investigates consumer preferences for self-defined fun and useful apps.

\section{WOMEN ADOPT AND DOMESTICATE TECHNOLOGY SLOWLY}

The pattern of women adopting technology slower than men has been seen over time with technologies such as the telephone, computers, the Internet, and mobile phones (Ewing \& Thomas 2010; Wajcman et al. 2008). In Australia, the female adoption rate for the Internet in 2007 was $71 \%$ increasing to 80\% in 2009 (Ewing \& Thomas 2010, 2). The average time online shows the most dramatic difference between the genders. In 2009 male users had on average been online longer than female users by around four months (Ewing \& Thomas 2010, 6). In 2007 the gap was around 16 months (Ewing \& Thomas 2010). This is a dramatic increase of female use of the Internet since the previous World Internet Project (WIP) survey in 2007. This shows that Australian women's adoption rate of the Internet when compared to that of Australian men is slow. This adoption trajectory can be seen in relation to the major technology developments over the last few decades including the mobile phone (Ewing \& Thomas 2010, Wajcman et al. 2008).

As women adopt technologies, two key differences emerge; women are seen to use technology in different ways and consumerisation occurs. Supriya Singh contends that 'as a technology becomes domesticated and feminised, gender differences are seen in the use of the technology rather than access' (Singh 2001, 396). Again this applies across all technologies. Early studies reported that men view the telephone primarily as a business tool (Fischer 1988; 
Wajcman et al. 2008) and women use it to maintain social contact (Fischer 1988; Lohan 2001; Wajcman et al. 2008).

\section{WOMEn AS NETWORKERS AND 'SOCIAL CONSUMERS'}

The use of technology for maintaining social bonds by Australian women can also be seen through their use of web 2.0 platforms. Australian women are frequent users of social networking sites (SNS) specifically Facebook, LinkedIn, Twitter and MySpace (Sensis 2011, 10), enabling them to maintain their image as being socially connected or for the purposes of this paper to act as Social Consumers. Reportedly the predominant use of SNS by Australian females is to 'catch up with friends and family' (96\%) (Sensis 2011, 19). According to the Sensis survey the majority of females using these sites are young women 14-39 who are most likely to visit the sites daily (Sensis 2011, 10). Older women 30+ are less frequent users of the sites and some never visit (ibid). Facebook is still the dominant SNS for Australians with 99\% of their Australian female participants using the site (Sensis 2011, 13).

Significantly for the purposes of this paper the devices being used to access social media are changing. Currently the device most used to access social media and to connect with friends and contacts is a laptop computer (Sensis 2011, 17). A laptop computer is the device most used among all age groups to access social media. However, smart-phone access is slowly catching up, with $31 \%$ of all females using a smart-phone to access social media (Sensis 2011, 17). This percentage increases to 52\% in the 14-19 age group (Sensis 2011, 17).

Part of the rationale for women to use social media and to act as 'Social Consumers' is their persistent role as emotional caregivers within the context of family and friends. In telephony studies Wajcman has reported that among Australians the highest calls made are between spouses $(18 \%)$, and by women to their children (13\%), parents $(11 \%)$, and extended family (12\%) (Wajcman et al. 2008, 18). Wajcman also reports that with texting, family (47\%), and friends (43\%) are the highest recipients of text messages (Wajcman et al. 2008, 19). Supporting this work is the recent Pew Internet report, which reveals that Americans are using SNS to keep in contact with close ties (Smith 2011). American 'women are slightly more likely than men to say that staying in touch with current friends is a major reason for using online social tools (70\% vs. 63\%)' (Smith 2011, 4). For an older age group such as those of middle age or older, 'female social media users are more likely than male users to cite family connections as a major reason for using these [social networking] sites (72\% vs. 55\%)' (Smith 2011, 4).

\section{'THE FRONTIER HAS BEEN TAMED' (Consalvo 2002, 132)}

The diffusion of the Internet among greater numbers of people made it mainstream. Becoming mainstream means 'the Internet often operates on a naturalised gender difference' (Paasonen 2002, 29). This has meant that websites and other online services are now targeted towards women, and they 'rarely promote deconstructive approaches to gender with their horoscopes and tips on relationships, home and food' (Paasonen 2002, 29). Consalvo's own research has detected that in the mid to late 1990s there was a push towards consumption and commodification, when businesses began to refine the idea that individuals could buy products online (Consalvo 2002, 131). When women began to adopt the Internet in greater numbers they became viewed as potential consumers and as an audience for online advertising (Consalvo \& Paasonen 2002, 8). Consalvo contends that,

'it is no accident that commerce has arrived in tandem with women. Women are an important demographic for marketers, and the Internet during this period has become more of a place for selling than for exploring or creating' (Consalvo 2002, 133).

When women went online the same discourses repeated in line with previous technologies. Women are now perceived and discussed in their traditional roles as social networkers as avid users of social networking sites (Sensis 2011), of e-Reading (Nielsen 2011) and now in the 
US a PEW report indicates that women especially older women are downloading more apps to tablets than men (Purcell 2011, 3).

In 2010 Ewing and Thomas revealed that 88\% of Australians currently use the Internet for product research prior to purchase $(2010,44)$, and more recently an ACMA report, ecommerce marketplace in Australia: Online shopping revealed that the 'majority of Internet users are online shoppers' in Australia (ACMA 2011, 1).

Indeed Australian women are well poised as potential consumers. Of the $4 \%$ of the Australian population who make purchases using a mobile phone $43 \%$ are women (ACMA 2011, 20). In keeping with their femininity (Paasonen 2002, 30) Australian women are shopping online for clothing/fashion and it is the highest product search conducted through social networking sites (Sensis 2011, 20).

\section{ABOUT THE STUDY}

This paper draws on data compiled from a larger study, Discovering Connectors: A Guide to The Australian Wireless End User (Rickard 2010), that investigates the ways in which Australian end users are adopting wireless broadband for individual use. The study is based on end user perspectives and explores the possibility that Australians are moving towards a sense of multimodal connectedness (Schroeder 2010) by using an increasing number of devices and forms of wireless connectivity. For many Australian end users wireless Internet connectivity takes the form of Mobile Broadband, Mobile Internet and WiFi, where Mobile Broadband is understood as using a USB 'dongle' or datacard in computers to connect to the Internet, mobile Internet as using a mobile phone or iPad/Tablet to connect to the Internet (3G), and WiFi as a fixed form of connectivity made available wirelessly, in public spaces like cafes, airports, libraries, and places of study. The data for the study was collected using an online questionnaire circulated in 2010. The research method applied involved collecting data through an online questionnaire, then the data was analysed using SPSS.

\section{PARTICIPANT RECRUITMENT}

Participants were recruited via email using networks which included industry and universities, and online advertisements on the University of the Third Age website and Australian Policy Online. An email was circulated through the networks mentioned above which included details about the project and how to participate. Respondent recruitment relied on the email snowballing through those networks. Participation in the online questionnaire was voluntary, and no incentives were offered for participation. The criteria for participation were deliberately broad. Participants needed to be at least 18 years of age and Australian residents. The questionnaire took approximately 15 minutes to complete; however times varied depending on the number of different forms of connectivity and devices used by respondents. Data was collected using Opinio software over a three-month period from June to August 2010.

172 participants aged between 18 and 69 answered the online questionnaire. Compared with the results reported in Australian studies such as those conducted by AIMIA (Mackay 2010, 2011) and the World Internet Project (Ewing and Thomas 2010) this study attracted only a small number of respondents. As a result of the small number of respondents, the conclusions drawn in this paper can only be indicative of adoption and usage practice in Australia. Respondents were residents of New South Wales (38.8\%), Victoria (35.9\%), Queensland (14.7\%), Western Australia (4.1\%), Australian Capital Territory (3.5\%), South Australia (2.4\%) and Tasmania (0.6\%.) The female respondents comprised 92 females aged between 18 and 63. The male respondents comprised 82 males aged between 22 and 69. ${ }^{1}$ 


\section{QUESTIONNAIRE STRUCTURE AND CONTEXT FOR THIS PAPER}

There were three sections to the questionnaire.

1. In the first section, participants were presented with a number of demographic questions relating to their age, living arrangements, marital status and employment status. No socio-economic questions were asked regarding income levels or education. Likewise the study was not structured to analyse the ways in which apps are used according to a range of other possible demographic characteristics. Hence participants were not asked questions relating to their ethnicity, language/s used, or disability and socio-economic status.

2. Following the first section, participants were asked a number of general questions about their use of communication technologies, such as 'How do you make telephone calls at home?' and 'Who pays for your internet connection at home?'

3. After this initial set of questions participants were required to indicate which type of internet connection they used when away from home and depending on their selection participants were sent down various paths of the questionnaire relating to their choice of wireless connectivity. If the participant did not use wireless connectivity they then exited the questionnaire.

Most of the questions in the online questionnaire presented the participants with multiple choices although there was an open comments box on each question for participants to contribute additional comments as they felt appropriate.

The context for this paper is two questions posed to participants who stated that they connect to the Internet using a mobile phone.

In Question 23 of the questionnaire participants were asked 'Which three phone apps do you find the most fun?'. Participants then entered their responses into a free text field. The following Question 24 asked respondents to enter into another free text field their responses to 'Which three phone apps do you find the most useful?'. The question was expressed this way to ensure that we recorded respondent preferences according to genre and delineated from what they downloaded and did not use.

The terms fun and useful are therefore subjective to the respondents and yet provide a form of measurement for the purposes of this paper. In total there were 52 fun app responses and 71 useful app responses.

\section{THE CONNECTOR TYPES}

Identified in the main report Discovering Connectors (Rickard 2010) were three discrete groups: Single Connectors, Twin Connectors and Triple Connectors. The Triple Connectors connect to the Internet using three types of wireless broadband: Mobile Broadband, Mobile Internet, and public Wi-Fi. The other two groups, 'Single Connectors' use one type of wireless broadband, and 'Twin Connectors' a combination of two.

In the main report the make up of the connector groups are: 


\begin{tabular}{|l|l|}
\hline \multirow{2}{*}{ Single $\mathrm{C}^{1}$} & Mobile Broadband \\
\cline { 2 - 2 } & Mobile Internet \\
\cline { 2 - 2 } Twin C & Wi-Fi \\
\hline \multirow{2}{*}{ Connectors } & Mobile Broadband + Mobile Internet* \\
\cline { 2 - 2 } & Mobile Broadband + Wi-Fi \\
\cline { 2 - 2 } & Mobile Internet + Wi-Fi \\
\hline Triple C & Triple Connectors C \\
Connectors & \\
\hline
\end{tabular}

* There were too few Mobile Broadband + Mobile Internet responses to analyse.

This paper focuses on the results and discussion in relation to the responses of only two of these connector groups: the Triple Connectors and the Single Connector group 'Mobile Internet'.

\section{PRofiLING THE TRIPLE CONNECTORS}

The Triple Connectors are the respondents who connect to the Internet using all three forms of wireless broadband: Mobile Broadband, Mobile Internet and WiFi. The Triple Connectors are the largest single group identified by the study, and make up $25.6 \%$ or 44 of all the respondents ${ }^{2}$. The gender breakup is 15 females between 18 and 50 years of age and 29 males between 27 and 66 years of age.

\begin{tabular}{|l|l|}
\hline \multicolumn{2}{|c|}{ Triple Connector Marital Status (male and female respondents) } \\
\hline Single & $25 \%$ \\
\hline Married and living with children & $34.1 \%$ \\
\hline In a relationship with no children & $13.6 \%$ \\
\hline Married with children, but none living at home & $11.4 \%$ \\
\hline Married with no children & $9.1 \%$ \\
\hline Single with children but none living at home & $2.3 \%$ \\
\hline In a relationship with children but none living at home & $2.3 \%$ \\
\hline
\end{tabular}

\begin{tabular}{|l|l|}
\hline \multicolumn{2}{|c|}{ Triple Connector Employment Status } \\
\hline Full time employed & $65.9 \%$ \\
\hline Full time students & $22.7 \%$ \\
\hline Employed part-time or casually & $15.9 \%$ \\
\hline Stay at home parent & $2.3 \%$ \\
\hline Retired & No responses \\
\hline Unemployed & No responses \\
\hline
\end{tabular}


The Mobile Internet Single Connectors make-up $15.1 \%$ or 26 of all the questionnaire respondents aged between 18 and 60 years of age ${ }^{3}$. Of these, nine are males aged between 23 and 60 years and 17 are females between 18 and 45 years of age.

\begin{tabular}{|l|l|}
\hline \multicolumn{2}{|c|}{ Mobile Internet Single Connectors Marital Status } \\
\hline Single & $42.3 \%$ \\
\hline Married and living with children & $30.8 \%$ \\
\hline In a relationship with no children & $19.2 \%$ \\
\hline Married with no children & $7.7 \%$ \\
\hline
\end{tabular}

\begin{tabular}{|l|l|}
\hline \multicolumn{2}{|c|}{ Mobile Internet Single Connectors Employment Status } \\
\hline Full time & $46.2 \%$ \\
\hline Full-time students & $34.6 \%$ \\
\hline Part-time or casually employed & $26.9 \%$ \\
\hline
\end{tabular}

\section{Social Consumers And Information SeEking Consumers}

Figure 1 below indicates the genre of apps preferred by the respondents. When the fun and useful apps are contrasted against each other the most popular apps by genre are social networking, weather, communication and navigation. 


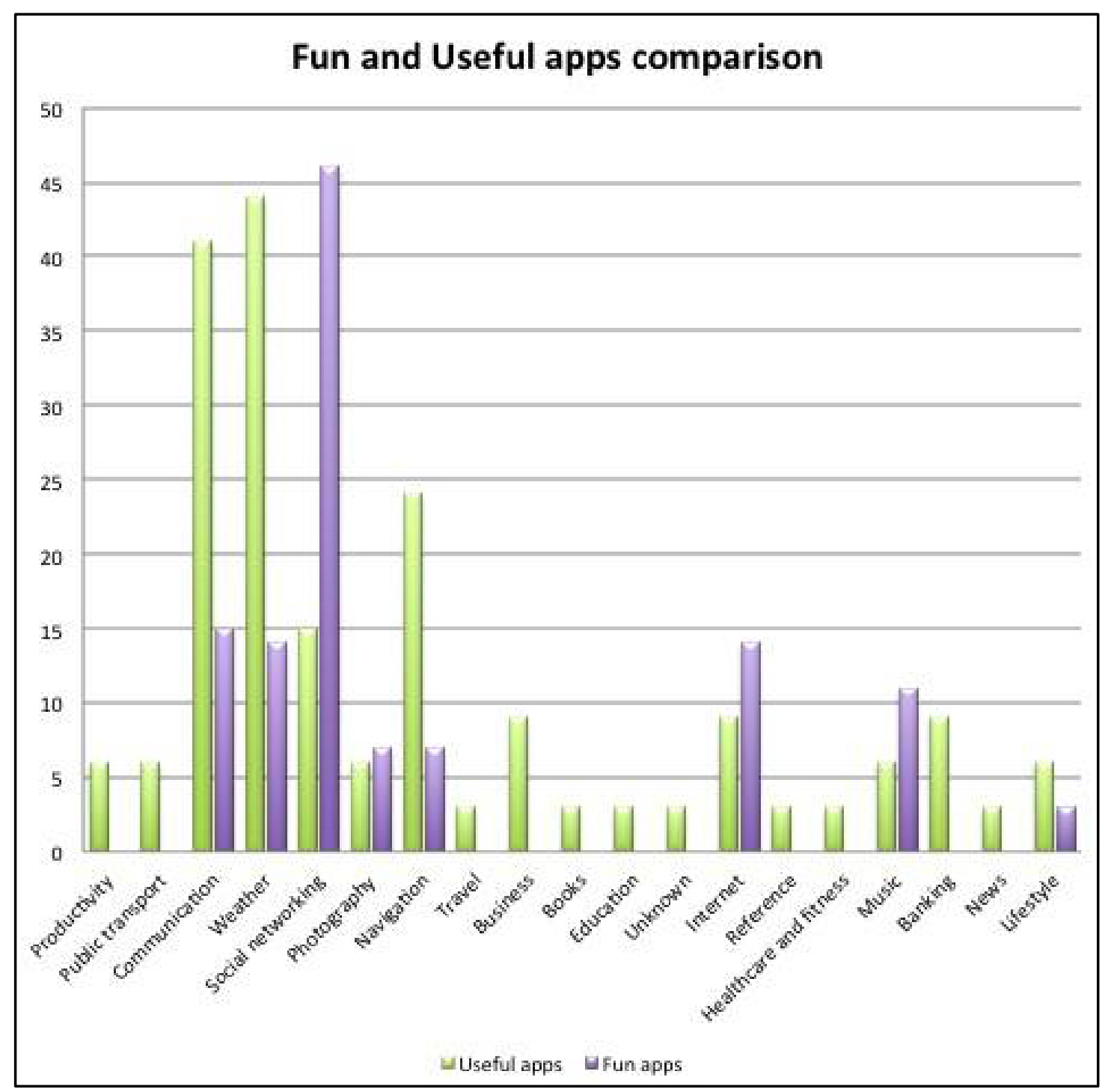

Figure 1 - Fun and Useful apps comparison

There is also a wider range of useful apps (19) to those that are considered fun (8) by respondents.

When the results of the Triple Connectors are contrasted with those of the Single Connectors they indicate two possible consumer groups: 'information seeking' and 'social'. The connectors who selected more apps of a genre considered to be seeking or looking up information are called 'information seeking consumers' and those connectors whose app selections reflected a greater range of social needs are called 'social consumers'.

In this next section of the paper the apps are organised according to whether they are fun or useful, and contrasted against whether they are being used by information seeking or social consumers. The data presented in the figures also reveals the gender preferences by app. 


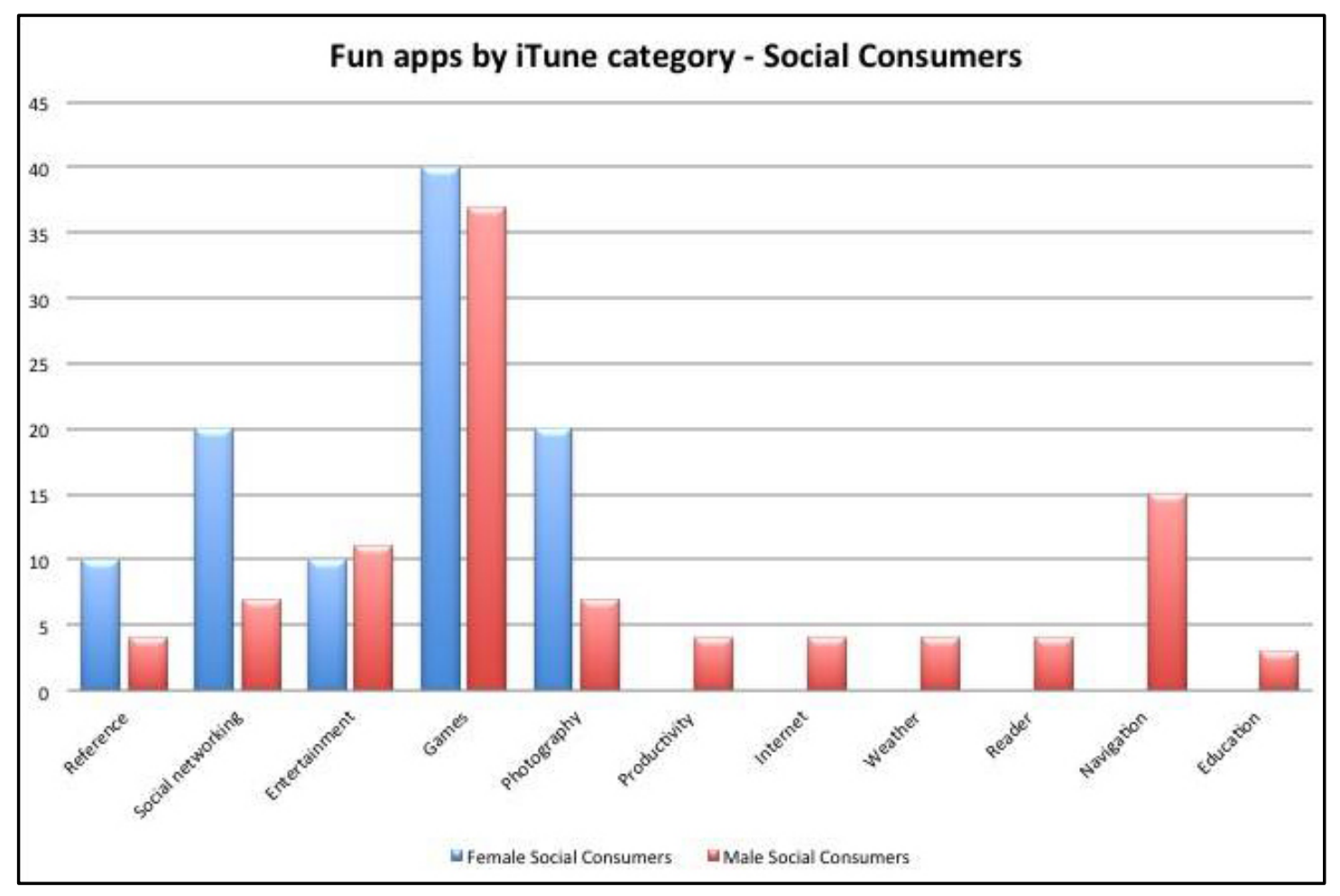

Figure 2 - Fun apps used by iTunes category - Social Consumers

In Figure 2, 58.6\% of male and $40 \%$ of females use fun apps. The male social consumers use a wider range of fun apps than the females.

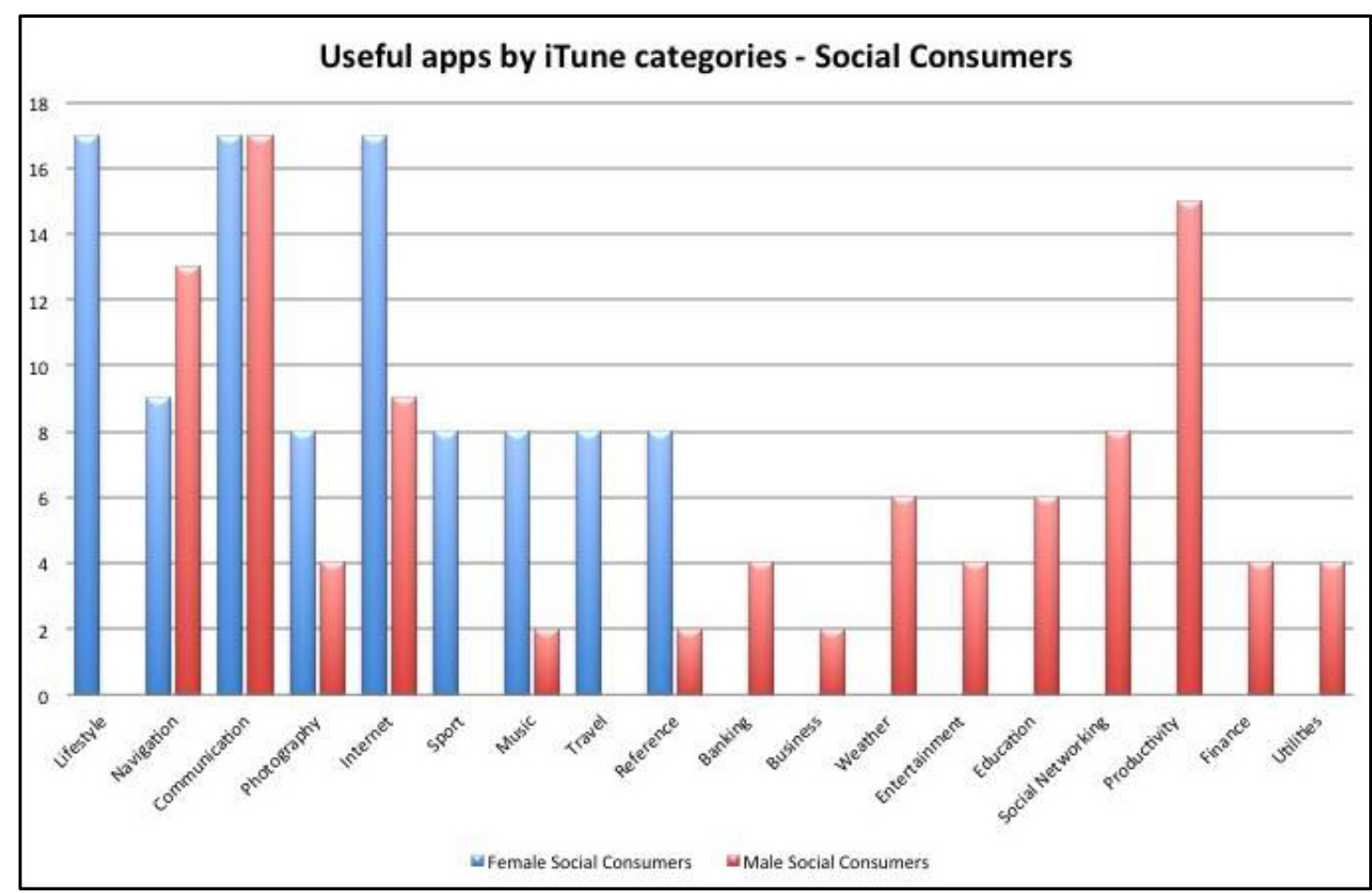

Figure 3 - Useful apps used by iTunes category - Social Consumers

In Figure 3, $79.3 \%$ of males and $46 \%$ of female Social Consumers use fun apps. In these results the men use a greater range of genres than women. 


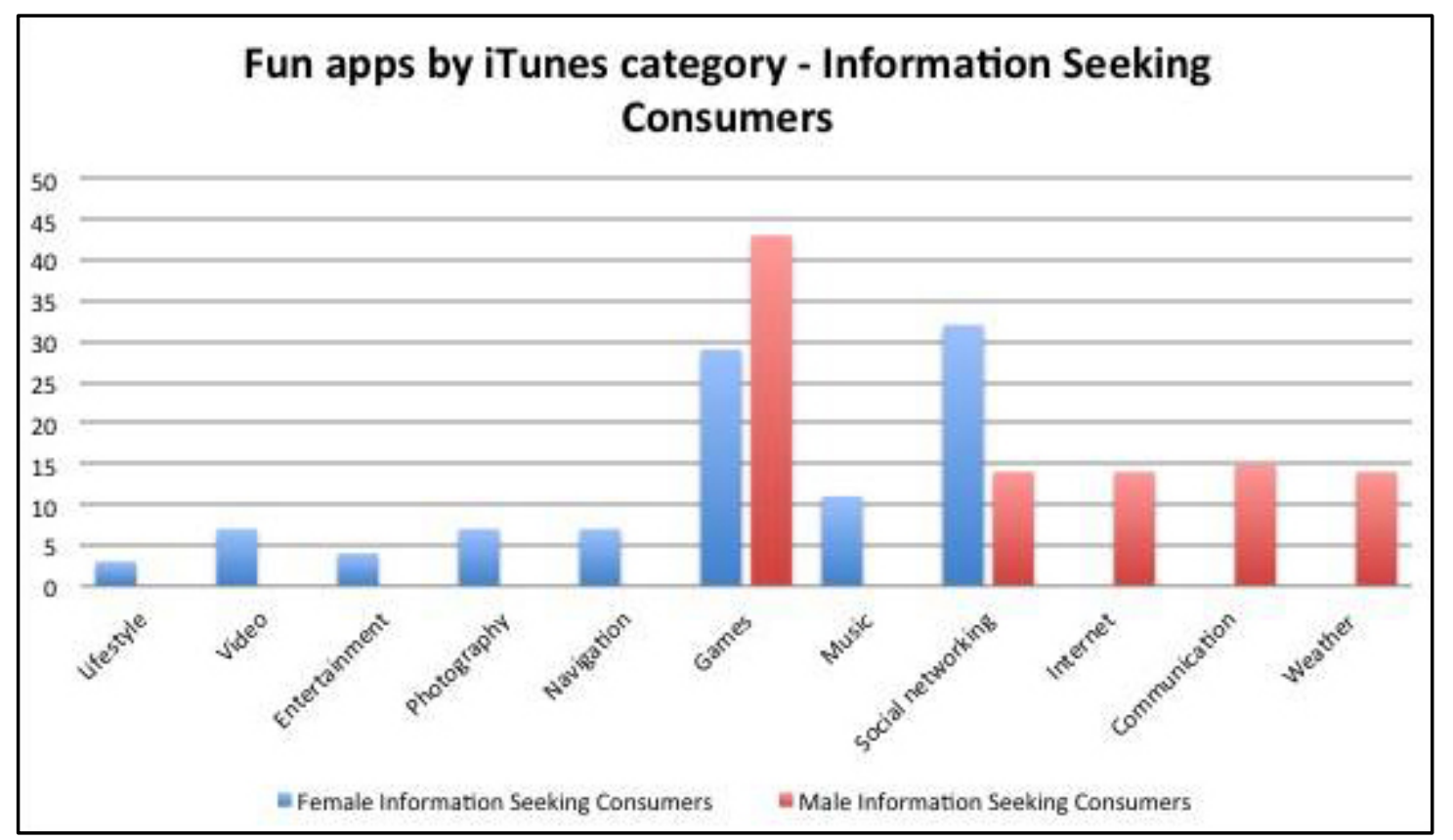

Figure 4 - Fun apps by iTunes category - Information Seeking Consumers

In Figure 4, 88.9\% of male and 64.7\% of female Information Seeking Consumers use fun apps on their phone. It can also be seen that the females use a wider range of apps in this category although the males use a greater number in concentrated genres overall. It is also apparent that the women, in greater numbers to the men, consider social networking a useful app.

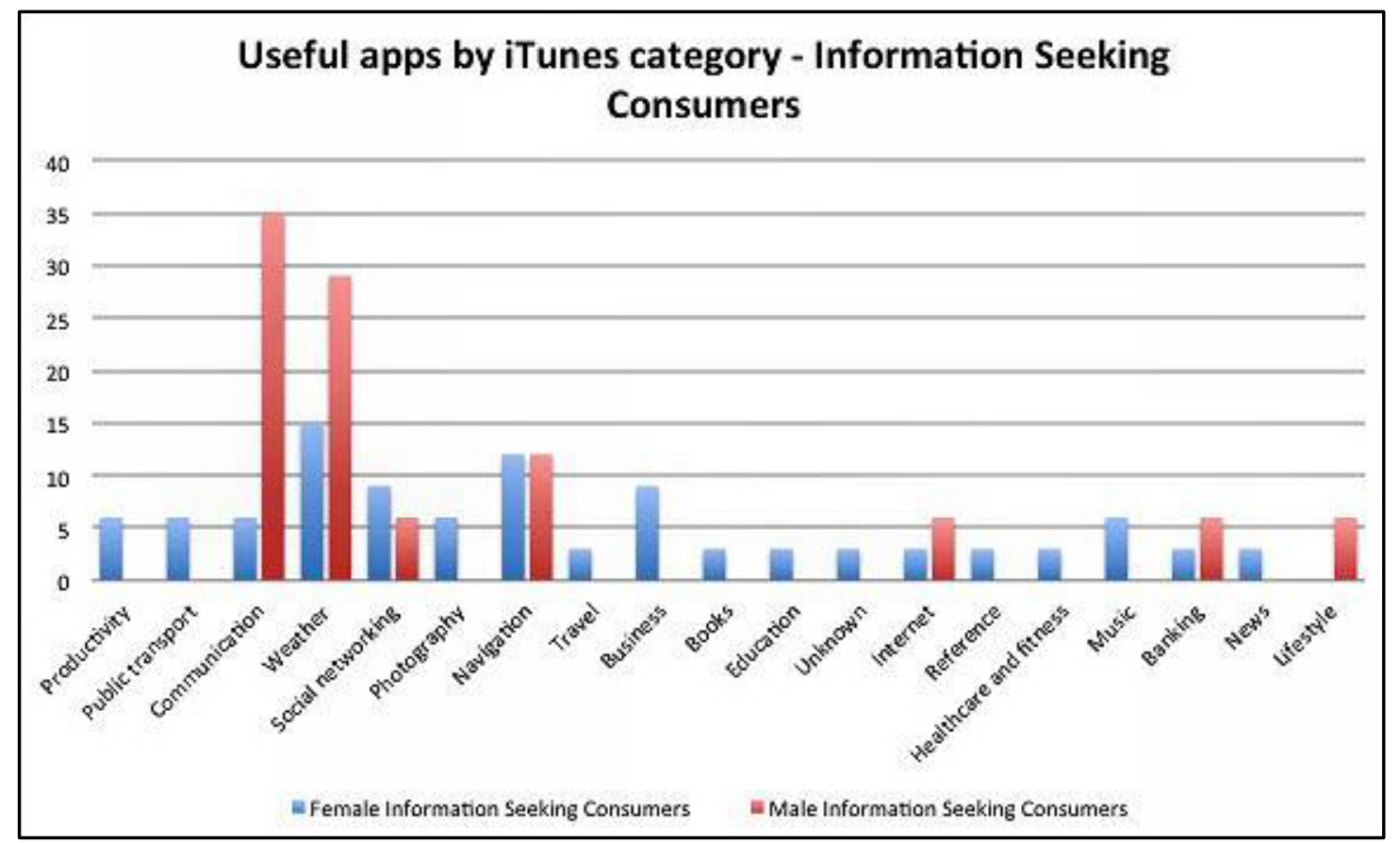

Figure 5 - Useful apps by iTunes category - Information Seeking Consumers

In Figure 5, 88.9\% of male and 70.6\% of female Information Seeking Consumers prefer the above categories of useful apps on their phones. It is also clear from Figure 6 that among this group the females use a wider range of apps than the males. 


\section{DISCUSSION}

The results indicate that Information Seeking Consumers prefer more 'useful' apps than the Social Consumers. The respondent data shows that our Information Seeking Consumers prefer the most apps overall when compared to those used by the Social Consumers.

The types of apps downloaded by both the Social Consumers and the Information Seeking Consumers were consistent with those recorded by AIMIA in the 2010 reporting period (Mackay 2010, 9). AIMIA respondents downloaded and installed games, maps and navigation, news, weather, instant messaging, social networking, photos and search applications (Mackay 2010).

As discussed earlier, women are slower to domesticate new technologies and services. There's a clear alignment between offline services such as newspapers, magazines and books migrating across into the app market. The uptake for these particular services has held wide appeal for women; older women in particular have adopted e-Readers and tablets such as the iPad. Sensis reports that $6 \%$ of Australian women reported using iPads or another tablet to access social media (Sensis 2011, 17).

Women's slow uptake of yet another form of technology - apps is also clear here in the results between the males and the females participating in the study. In all categories the female participants lag behind the males in app uptake. The greatest difference is between the social consumers $-79.3 \%$ of male Social Consumers download 'useful' apps whereas only $46.7 \%$ of female Social Consumers do, providing a remarkable difference of $32.6 \%$.

Another point of differentiation is between the spread of apps used. The situation differs between the Social Consumers and the Information Seeking Consumers. Among the Social Consumers the males download and prefer a wider range of apps. It is the female Information Seeking Consumers who download and prefer a wider range of fun and useful apps than the Information Seeking males.

\section{WOMEN AS SOCIAL CONSUMERS}

Our results indicate that the Social Consumers are entertainment focused, enjoying games (40\%), entertainment (10\%) photography (28\%) sport (8\%), music (8\%) and travel (8\%) along with their expected interest in communication; social networking (20\%) and communication (17\%). Social Consumers are able to increase their use of social networking sites through their phones and tablets because of the development of SNS-specific apps. These shortcut apps provide easy access to the existing online platform by removing the need to navigate through a browser and the use of such apps is often supported in Australia through unlimited social networking plans by telecommunication providers such as Telstra and Optus. Unlimited plans encourage further use of these apps potentially reducing the need to use traditional services such as voice, or even SMS.

It is interesting to note that overall Social Consumers use fewer apps than Information Seeking Consumers irrespective of gender. This suggests that while Social Consumers may spend time and money on entertainment they are less likely to spend as much time online as Information Seeking Consumers, and perhaps in the long run less money.

\section{Women As INFORMATION SEeking CONSUMERS}

A difference in the apps used by the Social Consumers as opposed to those used by Information Seeking Consumers is that apps designed to offer products and services are most likely to be standalone and not tied into an existing online platform like a SNS such as Facebook. Standalone apps designed specifically for use on phones and tablets are value added as they offer the potential to act as points of sale and Australians are interested in mobile commerce as recent figures indicate. Australian m-commerce doubled from $2 \%$ to $4 \%$ in the period from November 2009 to April 2011 (ACMA 2011, 4). 
Information Seeking Consumers are more likely to spend time monitoring their interests such as they are the group of consumers who spend most of their mobile online time checking emails, weather, reading online news and magazines (Rickard 2010). Spending time online while information seeking is possibly more likely to result in a transaction or sale. Searching is one of the most popular uses of the mobile Internet and searching while instore is increasingly popular (Moses 2011).

The ability of mobile apps to act as points of sale is likely to be especially important when the take-up of apps for everyday services such as grocery shopping actions reaches mass adoption levels. While it is currently possible to create grocery shopping lists using a mobile device it is possible to purchase your shopping list using your phone with only one large Australian supermarket chain. This is a distinct disconnect for the end users wanting to complete the transaction. A future trend highlighted by developments in Internet Protocol Television (IPTV) indicates that video tagging technology will make it possible to purchase items during the broadcast of a television show by simply selecting the item and then completing the transaction (Canning 2011). The use of augmentation or augmented reality in relation to apps, such as Layar could be another future possibility.

\section{CONCLUSION}

The adoption and domestication of mobile technologies by women has been consistent with the uptake of previous 'new' technology. Building on previous gender, intimacy and mobile communications research, this paper offers a needed 'snapshot' of the ways women are intentionally engaging with apps on their mobile devices. It can be seen that two distinct groupings of women, the 'Social Consumers' and the 'Information Seeking Consumers' choose and use a different range of apps.

Social Consumers are women who spend time online for entertainment purposes and for communicating with friends and family whereas the Information Seeking Consumers are more likely to be searching for information and performing tasks.

It is important to note that whilst this research aligns with previous work done on gendered uses of technology, intimacy and identity, it is always possible that through the use of mobile technologies 'gendered types of performance can be both reinforced and subverted' (Hjorth \& Kim 2004, 49). Hence whilst this article outlines the choices that women make to remain connected identities and highly social, the gendered use of technologies is not a simple matter and it is both socio-culturally and demographically nuanced.

It is also important to note in this study that women are again slow to adopt this new form of technology. The results show the slow adoption of apps by women compared with the men in the study, and the differences are not small. The minimum difference in uptake is $18.3 \%$ and the maximum $32.6 \%$. The results indicate that significant improvement can be made in the adoption rate of apps by women. Improvement can also be made on the part of app developers who perhaps need to consider the unique differences of the female market place. Female confidence and experience with technology could also play a part in the slow adoption rate.

Since technology is now clearly enmeshed in the everyday lives of women from domestic to communication technologies (Ewing \& Thomas 2010; Fischer 1988; Mackay 2010) further research is now required that investigates both qualitatively and quantitatively women's nuanced uses of apps on mobile phones. This research could focus on other possible demographic characteristics as well as compare usage across genders and cultures. 


\section{REFERENCES}

ACMA 2010. Communications report 2008-09, Australian Communications and Media Authority (ACMA), Canberra. Accessed 18 January 2010. Available from: $<\underline{\text { http://www.acma.gov.au/WEB/STANDARD/pc=PC 311972> }}$.

ACMA 2011. Communications report 2010-11. Series Report 1 - e-commerce marketplace in Australia: online shopping, Australian Communications and Media Authority (ACMA), Canberra. Accessed 1 October 2011. Available from: $<$ http://www.acma.gov.au/webwr/ assets/main/lib410148/cr_comp_report1-ecommerce_marketplace_in_aust-exec_summary.pdf $>$.

AIMIA 2010 Australian Mobile Phone Lifestyle Index 6th Edition - Special Topic: Mobile Phone Applications, Australian Interactive Media Industry Association Mobile Industry Group. Accessed 15 November 2011. Available from: $<$ http://www.aimia.com.au/enews/events/AMPLI\%202010/101002\%20AIMIA_Report_Fi nal.pdf $>$

Canning, S. 2011. 'Touch and it's yours while the show goes on', The Australian, November 21, p. 24.

Consalvo, M. 2002. 'Selling the Internet to women', in M Consalvo \& S Paasonen (eds), Women \& Everyday Uses of the Internet: agency \& identity, Peter Lang, New York, 111 138.

Consalvo, M; Paasonen, S. 2002. 'On the Internet, women matter' in M Consalvo \& S Paasonen (eds), Women \& Everyday Uses of the Internet: agency \& identity. New York: Peter Lang, 1-18.

Ewing, S; Thomas, J. 2010. CCi Digital Futures 2010: The Internet in Australia, ARC Centre of Excellence for Creative Industries and Innovation, Swinburne University of Technology, Victoria. Accessed 1 July 2011. Available from: $<$ www.cci.edu.au/projects/digital-futures $>$.

Fischer, C. 1988. "Touch someone': the telephone industry discovers sociability' Technology and Culture, vol. 29, no. 1, 32-61.doi:10.2307/3105226.

Fraser, H. 2011. 'There's an App for that' Communications Policy and Research Forum. Network Insight Institute, Sydney, 98-104. Accessed 20 Nov 2011. Available from: $<$ http://www.networkinsight.org/events/cprf2011.html/group/6 > .

Goggin, G. 2006. Cell Phone Culture: Mobile Technology in Everyday Life. London \& New York: Routledge.

Green, E. 2001. 'Technology, leisure and everyday practices', in E Green \& A Adams (eds), Virtual Gender: Technology Consumption and Identity. Hoboken: Routledge.136-148.

Hjorth, L; Kim, H. 2004. 'Being there: society of the phoneur gendered customising of mobile telephonic net practices in Seoul'. Proceedings of Seoul Conference on Mobile Communication: Hallym University. 18-19 October; Chuncheon, Korea: 237-242.

Licoppe, C. 2004. 'Connected' presence: the emergence of a new repertoire for managing social relationships in a changing communication technoscape. Environment \& Planning D: Society \& Space, 22 (1): 135-156.

Lloyd, C. 2010. “Intimate mobile connections: a tool for intimacy”. Media, Democracy \& Change: Australian and New Zealand Communication Association (ANZCA) Conference 2010, 07/07/2010. Old Parliament House, Canberra: University of Canberra. 
Lohan, M. 2001. 'Men, masculinities and 'mundane', in E Green \& A Adams (eds), Virtual Gender: Technology Consumption and Identity. Hoboken: Routledge. 149-161.

Mackay, M. 2010. Australian Mobile Phone lifestyle Index: Mobile Phone Applications. Australian Interactive Media Industry Association Mobile Industry Group. Accessed 20 Oct 2011. Available from: <http://www.aimia.com.au/enews/events/AMPLI 2010/101002 AIMIA_Report_Final.pdf $>$.

Mackay, M. 2011. Australian Mobile Phone Lifestyle Index: Mobile Phone Advertising and Marketing. Australian Interactive Media Industry Association Mobile Industry Group. Accessed 20 Oct 2011. Available from: $<$ http://www.aimia.com.au/enews/events/AMPLI\%202011/AMPLI\%20Report2011 FINA L.pdf $>$

Moses, A. 2011. 'Australia's white hot smartphone revolution', The Age. Accessed 8 September 2011. Available from: < http://www.theage.com.au/digitallife/mobiles/australias-white-hot-smartphone-revolution-20110908-1jz3k.html>

Nielsen 2011. 'Changing Demographics of Tablet and e-Reader owners'. Accessed 20 October 2011. Available from: < http://blog.nielsen.com/nielsenwire/online mobile/changingdemographics-of-tablet-and-ereader-owners-in-the-us/>.

Paasonen S. 2002. 'Gender, identity, and (the limits of play) on the Internet', in M Consalvo \& S Paasonen (eds), Women \& Everyday Uses of the Internet: agency \& identity. New York: Peter Lang. 21-39.

Purcell, K. 2011. 'Half of adult cell phone owners have apps on their phones'. Pew Internet \& American Life Project, November 2011. Accessed 5 November 2011. Available from: $<$ http://pewinternet.org/Reports/2011/Apps-update.aspx > .

Rickard, S. 2010. Discovering Connectors: A Guide to The Australian Wireless End User. Smart Services CRC, unpublished.

Sensis 2011. 'Sensis Social Media Report: What Australian people and businesses are doing with social media'. Accessed 20 November 2011. Available from: $<$ http://www.aimia.com.au/enews/Membership/Members_Only/SENSIS_SOCIAL_MEDI A_REPORT_May2011.pdf>.

Smith, A. 2011. Why Americans use social media: social networking sites are appealing as a way to maintain contact with close ties and reconnect with old friends, Pew Internet \& American Life Project, November 2011. Accessed 5 November 2011. Available from: $<$ http://pewinternet.org/ /media//Files/Reports/2011/Why Americans Use Social Media.pdf $>$.

Singh S. 2001. 'Gender and the use of the internet at home', New Media \& Society,3 (4): 395416.

Sterne, J. 2003. The Audible Past. Cultural origins of sound reproduction. Durham \& London: Duke University Press.

Wajcman, J; Bittman, M; Jones, P; Johnstone, L; Brown, JE. 2008. The impact of the mobile phone on work/life balance: final survey report, Australian Mobile Telecommunications Association. Accessed 09 August 2009. Available from:

$<$ http://polsc.anu.edu.au/staff/wajcman/pubs/Mobile_phone final\%20survey\%20report 27 Mar08.pdf> 


\section{ENDNOTES}

1. $\mathrm{M}=37 ; \mathrm{SD}=13.43$

2. $\mathrm{M}=44.11, \mathrm{SD}=13.54$

3. $\mathrm{M}=31.92, \mathrm{SD}=14.224$

Cite this article as: Rickard, Scott; Lloyd, Clare. 2012. 'Consuming apps: the Australian woman's slow appetite for apps'. Telecommunications Journal of Australia 62 (4): 62.1 62.15. Available from: http://tia.org.au. 